\title{
BMJ Open Proportion of women presenters at medical grand rounds at major academic centres in Canada: a retrospective observational study
}

\author{
Danielle Buell, ${ }^{1}$ Brenda R Hemmelgarn, ${ }^{2}$ Sharon E Straus ${ }^{1,3}$
}

To cite: Buell D,

Hemmelgarn BR, Straus SE.

Proportion of women presenters at medical grand rounds at major academic centres in Canada: a retrospective observational study. BMJ Open 2018;8:e019796. doi:10.1136/ bmjopen-2017-019796

- Prepublication history for this paper is available online. To view these files, please visit the journal online (http://dx.doi. org/10.1136/bmjopen-2017019796).

Received 26 September 2017 Revised 17 November 2017 Accepted 22 November 2017

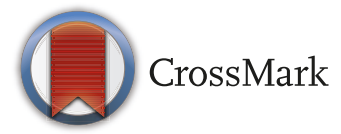

${ }^{1}$ Department of Medicine, University of Toronto, Toronto, Ontario, Canada

${ }^{2}$ Departments of Community Health Sciences and Medicine, University of Calgary, Calgary, Alberta, Canada

${ }^{3}$ Li Ka Shing Knowledge Institute, St Michael's Hospital Toronto, Ontario, Canada

Correspondence to

Dr Danielle Buell;

danielle.buell@mail.utoronto.ca

\section{ABSTRACT}

Objective To assess the proportion of women who presented research or medical grand rounds at five major academic hospitals in Canada.

Design A cross-sectional study.

Setting Five major university-affiliated hospitals in Toronto and Calgary.

Results Overall, at all sites and types of academic rounds, there were an average of $17 \%$ fewer women presenting than men $(\mathrm{P}<0.001)$. There were an average of $32 \%$ and $21 \%$ more men presenting at the city-wide grand rounds in cities $A$ and $B$, respectively $(P<0.001$, $P=0.002$ ). There were more male speakers at four out of five types of rounds. The proportion of women presenting on average was proportional to the Canadian workforce, but on average, below the proportion of female residents and medical students (median ratio 1.1, 0.7 and 0.8, respectively).

Conclusion Our study demonstrated a lower proportion of females in an important outlet for academic recognition and role modelling. This provides a possible contributing factor to the under-representation of women in academic medicine and an area that can be systematically targeted to promote equity.

\section{INTRODUCTION}

Despite the increasing number of women enrolled in North American medical schools, there is a persistent disparity in female representation within academic medicine. There is a larger proportion of male faculty, ${ }^{1}$ women are remunerated less for similarly ranked medical and academic positions and there is a discernible under-representation of women in editorial positions and female-led publications within major biomedical journals. ${ }^{2-6}$ In 2015 , only 1 of 16 deans of medical faculty $(6 \%)^{7}$ and 2 of 15 chairs of departments of medicine in Canada were female.

Several reasons for the discrepancies have been explored, including lack of female mentorship, difficulties with research establishment, family-work life balance and a proclivity for male-dominated faculty. ${ }^{8}$ The lack of women
Strengths and limitations of this study

Data from multiple centres and different types of rounds were included.

- Every medical grand rounds at major academic hospitals in Toronto and Calgary were included.

- Results were compared with national proportions.

- The process by which each centre selects speakers for grand rounds was unknown to the authors.

- Gender was inferred by name and photo, not by asking the presenter directly.

in academic institutions has been well described, particularly with respect to gender disparities in research productivity and presentation. ${ }^{1011}$

Within academic teaching hospitals in Canada, grand rounds provide an important outlet for external exposure and dissemination of scholarly achievements, contributing to academic merit and promotion. Recent studies have described a discrepancy between the proportion and speaking time of women and men presenting at grand rounds ${ }^{12}$ and at major international conferences. ${ }^{13} 14$ Given the importance of exposure to colleagues and trainees during large format presentations, there is concern that such systematic disparities preclude women from academic advancement. Additionally, this limits potential mentorship and role modelling opportunities for female trainees. We conducted a retrospective study to assess the proportion of females that presented at research rounds or grand rounds at five major academic hospitals in Canada, from 2011 to 2015. The objective of this study was to identify whether a systematic discrepancy exists and to inform efforts addressing the gender gap within the academic and medical community.

\section{METHODS}

We collected publicly available names and dates of presenters at rounds at five major 
university-affiliated hospitals in Toronto (four) and Calgary (one), between 2011 and 2015. For Calgary, these included the Department of Medicine city-wide grand rounds (CWGR) and the Department of Community Health Sciences/O'Brien Institute for Public Health Seminar series (clinical research rounds (CRR)). In Toronto these included CWGR, medical grand rounds (MGRs), CRR, popular science lectures (pop science) and basic science research rounds (BSRR). To avoid selection and information bias, we identified and included all eligible rounds and speakers in the analysis. Raw data were compiled by individuals blinded to the study intent. Gender was determined by the authors based on the name of the presenter; if there was ambiguity, then the authors determined the gender based on photos. To our knowledge, there is no formal system for selecting presenters; currently, they are invited at the discretion of the organising committee. Any individual can present, regardless of their association with an institution. Each type of rounds targets a different population of medical professionals. MGR are presentations attended by and targeted to the department of medicine at each individual hospital including faculty, residents and medical students. CWGR are select MGRs that are broadcasted to all the teaching hospitals in the city. The different research-specific rounds, CRR and BSRR, target health service researchers and basic science researchers, respectively. Finally, the pop science lectures target high school students.

The percentage of rounds presented by at least one female speaker was calculated for each calendar year and type of rounds. We compared our results with workforce data, including the national proportion of female internal medicine physicians, residents, medical students, with values of $37 \%, 49 \%$ and $57 \%$, respectively. ${ }^{7}$ The proportion of female faculty in internal medicine at both the University of Calgary and University of Toronto was $35 \%$, thus comparable with the national average, so it was not included in the analysis. A simple t-test was used to compare the mean percentages of female and male speakers, and a one-sample t-test was used to compare the mean proportion of female speakers with the national proportion of female internists, medical students and residents. The ratio of mean female speakers to workforce data was calculated by dividing the mean female speakers at each type of rounds over the national proportions. A linear regression was used to analyse proportion of women speakers over time. Any data that were not available were not included in the statistical analysis.

\section{RESULTS}

There were a total of 1296 rounds that were included. Five hundred and forty-six rounds $(42.1 \%)$ had at least one female speaker. The percentage of female speakers and number of rounds, by site and type, are illustrated in table 1 . On average, there were $17 \%(\mathrm{P}=<0.001)$ more male speakers than female speakers at all hospitals from 2011 to 2015. Eight out of 11 types of rounds had a lower mean proportion of female speakers compared with the mean proportion of female medical students in Canada, 7 out of 10 compared with the proportion of residents and 4 out of 10 compared with the proportion of female internist (table 2).

Table 1 Proportion of rounds with at least one female speaker from 2011 to 2015 based on site and type of rounds

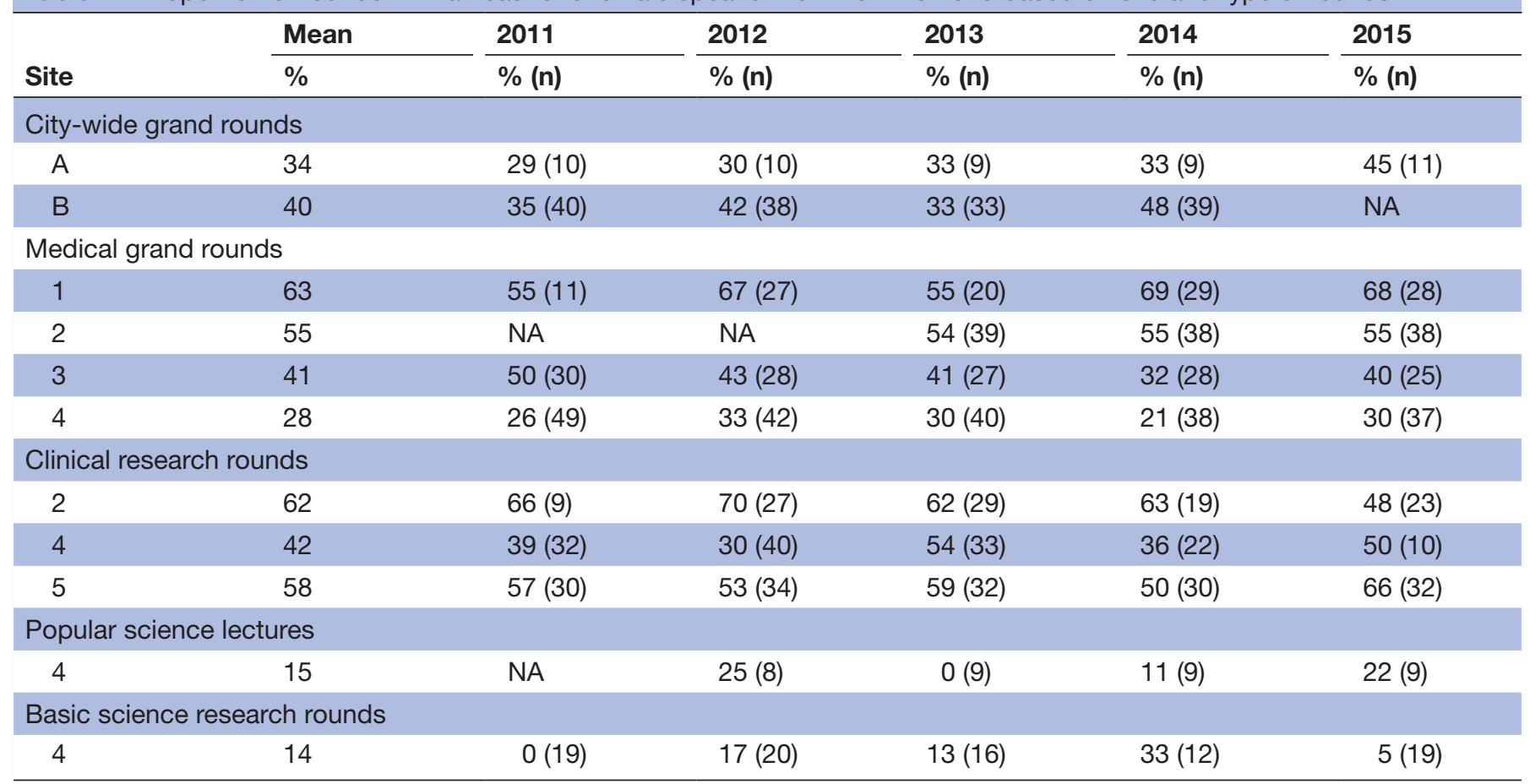

NA, not available. 
Table 2 Difference between mean women presenters at each type of rounds between 2011 and 2015 and the national proportions of females within internal medicine, residents within internal medicine and medical students

\begin{tabular}{|c|c|c|c|c|}
\hline \multirow[b]{3}{*}{ Site } & \multirow[b]{2}{*}{ Mean } & \multicolumn{3}{|c|}{ Difference from national mean } \\
\hline & & $\begin{array}{l}\text { Medical } \\
\text { students }\end{array}$ & Residents & Staff \\
\hline & $\%$ & $\begin{array}{l}\text { National } \\
\text { mean }=57 \%\end{array}$ & $\begin{array}{l}\text { National } \\
\text { mean=49\% }\end{array}$ & $\begin{array}{l}\text { National } \\
\text { mean }=37 \%\end{array}$ \\
\hline \multicolumn{5}{|c|}{ City-wide grand rounds } \\
\hline$A$ & 34 & $23^{*}$ & $15^{\star}$ & 3 \\
\hline $\mathrm{B}$ & 40 & $17^{*}$ & 9 & -3 \\
\hline \multicolumn{5}{|c|}{ Medical grand rounds } \\
\hline 1 & 63 & $-6^{*}$ & $-14^{\star}$ & $-26^{\star}$ \\
\hline 2 & 55 & 2 & $-6^{*}$ & $-18^{\star}$ \\
\hline 3 & 41 & $16^{*}$ & 8 & -4 \\
\hline 4 & 28 & $29^{*}$ & $21^{\star}$ & $9^{*}$ \\
\hline \multicolumn{5}{|c|}{ Clinical research rounds } \\
\hline 2 & 62 & -5 & $-13^{*}$ & $-25^{\star}$ \\
\hline 4 & 42 & $15^{\star}$ & 7 & -5 \\
\hline 5 & 58 & -1 & $-9^{*}$ & $-21^{*}$ \\
\hline \multicolumn{5}{|c|}{ Popular science lectures } \\
\hline 4 & 15 & $42^{*}$ & $34^{*}$ & $22^{*}$ \\
\hline \multicolumn{5}{|c|}{ Basic science research rounds } \\
\hline 4 & 14 & $43^{\star}$ & $35^{\star}$ & $23^{*}$ \\
\hline
\end{tabular}

${ }^{*} \mathrm{P}<0.05$

As described in table 3, at MGRs, some centres had up to an average of $44 \%$ more male speakers, while others had an equal percent of or more female speakers. There

Table 3 Mean difference between percentage of rounds with male $(\mathrm{M})$ or female $(\mathrm{F})$ speakers, between 2011 and 2015, at medical grand rounds (MGRs), city-wide grand rounds (CWGRs) and clinical research rounds (CRRs) based on site

\begin{tabular}{ccc}
\hline \multicolumn{3}{l}{ Mean difference between } \\
Site & M and F (\%) & P value \\
\hline CWGR & & \\
A & 32 & $<0.001$ \\
B & 21 & 0.002 \\
MGR & & \\
\hline 1 & -26 & $<0.001$ \\
\hline 2 & -9 & $<0.001$ \\
3 & 18 & $<0.001$ \\
\hline 4 & 44 & $<0.001$ \\
CRR & & \\
\hline 2 & -24 & 0.001 \\
\hline 4 & 16 & 0.015 \\
\hline 5 & -16 & 0.003 \\
\hline
\end{tabular}

Table 4 Mean difference between percentage of rounds with male $(\mathrm{M})$ or female $(\mathrm{F})$ speakers between 2011 and 2015 at all sites, by type of rounds, across two cities

\begin{tabular}{llc}
\hline & $\begin{array}{l}\text { Mean difference } \\
\text { between } \mathbf{M} \text { and }\end{array}$ & \\
Type of rounds & $\mathbf{F ~ ( \% )}$ & P value \\
\hline City-wide grand rounds & 27 & $<0.001$ \\
Medical grand rounds & 8 & 0.05 \\
Clinical research rounds & -7 & 0.06 \\
Popular science lectures & 77 & $<0.001$ \\
Basic science & 73 & $<0.001$ \\
research rounds & & \\
\hline
\end{tabular}

was an average of $32 \%$ and $21 \%$ more male speakers than females at CWGRs at sites A and B, respectively. At CRR, site 4 had $16 \%$ more male than female speakers, while sites 2 and 5 had $24 \%$ and $16 \%$ more female speakers, respectively. Based on the type of rounds, there was a higher percentage of male speakers at every type of rounds except CRR (table 4).

The median normalised ratio of the proportion of women presenting to workforce data of female internal medicine physicians, residents and medical students were 1.1, 0.7, and 0.8, respectively (figure 1). There was no statistically significant change in proportion of female presenters over time $(\mathrm{P}=0.723)$.

\section{DISCUSSION}

The data illustrate that over the past 5 years, there have been fewer female presenters at four out of five different types of rounds at five major academic hospitals in Canada. This results in a potential missed opportunity to expose trainees to female leaders, which can be an essential component of supporting female advancement in academic medicine. Previous reports suggest that such disparities contribute to the steady attrition of women in academic medicine as they create an environment that is unsupportive and lacking mentorship. ${ }^{15}$

To mitigate this potential impact, we have to understand the cause. Possible explanations for this discrepancy are a shortage of female physicians and scientists willing to present or perhaps women are not being invited to present because they are not in decision-making positions for academic meetings. ${ }^{14}$ Encouragingly, our workforce data demonstrated that the proportion of female presenters is comparable with the workforce, and 4 out of 11 types of rounds had statistically significantly higher proportion of females speakers than the proportion of the national workforce. However, the proportion of female speakers was consistently lower than the proportion of trainees who are women, suggesting one of the root causes is the gender gap in academic medicine itself. 
Ratio of Women Presenters to Workforce and Trainees

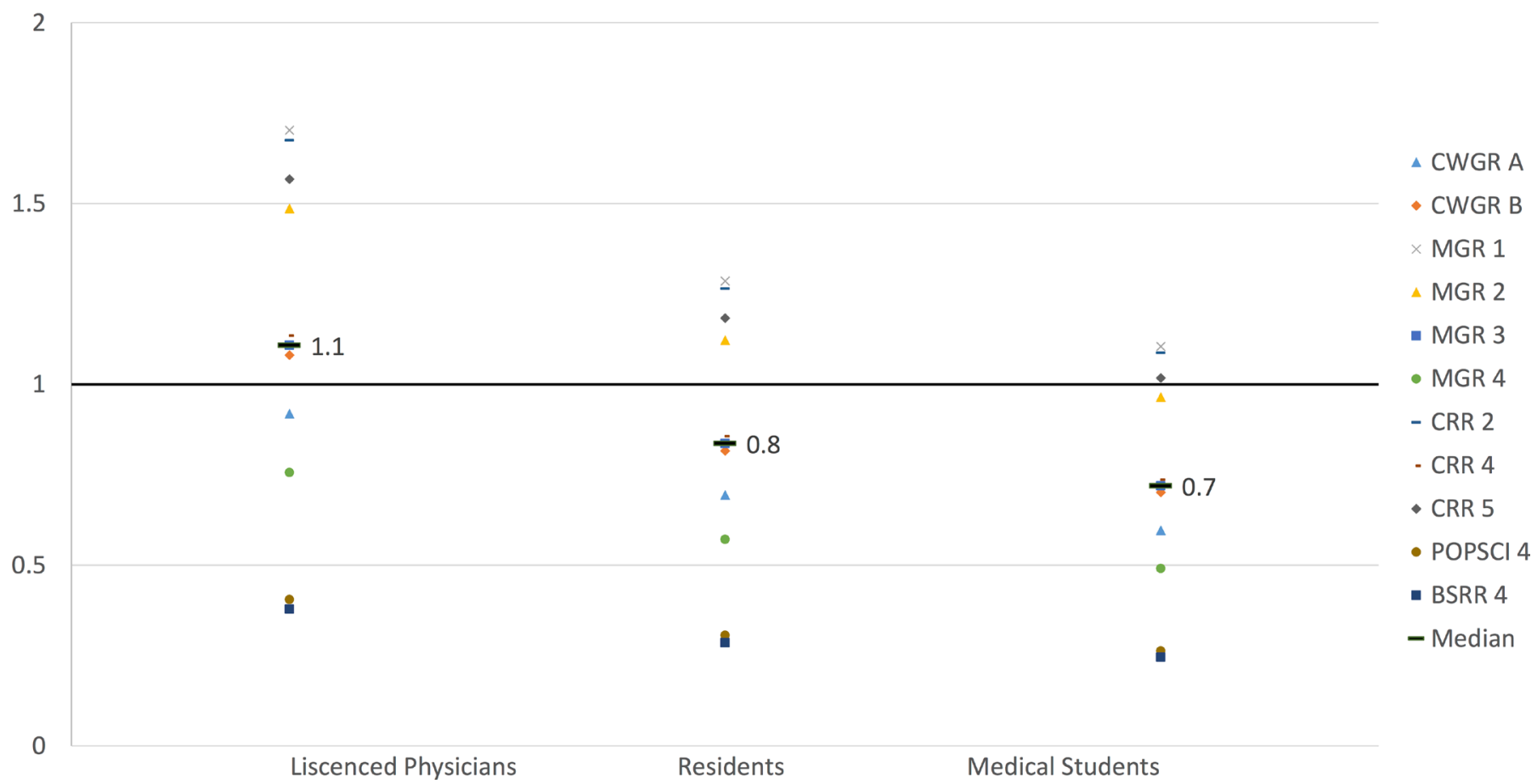

Figure 1 Proportion of women presenters by site and type of rounds between 2011 and 2015, normalised to proportion of women within internal medicine, residents in internal medicine and medical students. BSRR, basic science research rounds; CRR, clinical research rounds; CWGR, city-wide grand rounds; MGR, medical grand rounds, POPSCI, popular science lectures.

The aim of this report was to look at the representation of female presenters at academic grand rounds across programmes in Canada; however, there are some limitations to the study. One limitation is our lack of understanding of how these programmes recruit speakers and how some can achieve nearly equal representation. To our knowledge, the speaker invitations are at the discretion of the organising administration or committee, and there is no formal system for invitations. This approach would allow for the introduction of a standardised approach to promote equity in large format presentation settings. Another limitation of the retrospective and observational study design was the preclusion of obtaining the information on gender from the presenters themselves, instead the authors inferred gender based on the presenters name and photo. Additionally, we compared the proportion of female presenters to national workforce data in an attempt to represent the denominator of women available to present. Although this comparison does provide us insight into the proportional representation of women in medicine, it does not truly represent the denominator. The denominator cannot be truly quantified given speakers are invited internationally and across scientific disciplines. Finally, our data represent a 5-year period, during which there was no significant increasing or decreasing trend in the proportion of female speakers. A greater follow-up period would be useful to explore in a future study.
Established methods to engage women in medicine have been shown to be successful. For example, a study assessing the impact of women-specific programming to actively support females in all roles within academic medicine, reported improvements in internal partnerships, an increase in females in leadership roles and a rise in job retention and satisfaction. ${ }^{15}$ Increasing the number of females presenting at academic conferences targets one aspect of the gender inequity in academic medicine. Carnes $e t a l^{16}$ provide a set of recommendations to address gender linked biases that marginalise females in academia; these include implementing policies that promote institutional support for programmes with diverse representation in large format presentations. They advocate that such efforts promote female advancement and are directly tied to advances in socialised differences affecting women's health. We believe that future research should address how we can engage women in presenting at various academic rounds and ensuring that women are represented to allow role modelling for trainees and junior faculty.

Contributors SES is responsible for the conception of the study, and DB is responsible for the analysis and interpretation of the data. All authors critically revised the manuscript and added important intellectual content. All authors participated in the work and have read and approved the manuscript.

Funding This research received no specific grant from any funding agency in the public, commercial or not-for-profit sectors.

Competing interests None declared. 
Provenance and peer review Not commissioned; externally peer reviewed.

Data sharing statement Extra data can be accessed via the Dryad data repository at http://datadryad.org/ with the doi: 10.5061/dryad.b43gf.

Open Access This is an Open Access article distributed in accordance with the Creative Commons Attribution Non Commercial (CC BY-NC 4.0) license, which permits others to distribute, remix, adapt, build upon this work non-commercially, and license their derivative works on different terms, provided the original work is properly cited and the use is non-commercial. See: http://creativecommons.org/ licenses/by-nc/4.0/

(C) Article author(s) (or their employer(s) unless otherwise stated in the text of the article) 2018. All rights reserved. No commercial use is permitted unless otherwise expressly granted.

\section{REFERENCES}

1. Lautenberger D, Dander V, Raezer C, et al. The state of women in academic medicine: the pipeline and pathways to leadership: Association of American Medical Colleges,2014 https://www.aamc. org/members/gwims/ statistics/ (accessed Sept 2017).

2. Wright AL, Ryan K, St Germain P, et al. Compensation in academic medicine: progress toward gender equity. J Gen Intern Med 2007;22:1398-402.

3. Carr PL, Gunn CM, Kaplan SA, et al. Inadequate progress for women in academic medicine: findings from the National Faculty Study. $J$ Womens Health 2015;24:190-9.

4. Jena $A B$, Olenski AR, Blumenthal DM. Sex differences in physician salary in us public medical schools. JAMA Intern Med 2016;176:1294-304.
5. Burden M, Frank MG, Keniston A, et al. Gender disparities in leadership and scholarly productivity of academic hospitalists. $J$ Hosp Med 2015;10:481-5.

6. Jagsi R, Griffith KA, Stewart A, et al. Gender differences in the salaries of physician researchers. JAMA 2012;307:2410-7.

7. Bourgeois L, Kealey L. Canadian medical education statistics: The Association of Faculties of Medicine of Canada, 2015. https://afmc. $\mathrm{ca} / \mathrm{sites} /$ default/files/CMES2016-reduced.pdf (accessed Mar 2017)

8. Fridner A, Norell A, Åkesson G, et al. Possible reasons why female physicians publish fewer scientific articles than male physicians - a cross-sectional study. BMC Med Educ 2015;15:67.

9. Levine RB, Lin F, Kern DE, et al. Stories from early-career women physicians who have left academic medicine: a qualitative study at a single institution. Acad Med 2011;86:752-8.

10. Ovseiko PV, Greenhalgh T, Adam P, et al. A global call for action to include gender in research impact assessment. Health Res Policy Syst 2016;14:50.

11. Eloy JA, Svider PF, Cherla DV, et al. Gender disparities in research productivity among 9952 academic physicians. Laryngoscope 2013;123:1865-75.

12. Boiko JR, Anderson AJM, Gordon RA. Representation of women among academic grand rounds speakers. JAMA Intern Med 2017:177:722-4.

13. Metaxa V. Is this (still) a man's world? Crit Care 2013;17:112.

14. Modra LJ, Austin DE, Yong SA, et al. Female representation at Australasian specialty conferences. Med J Aust 2016;204:385.

15. Bauman MD, Howell LP, Villablanca AC. The women in medicine and health science program: an innovative initiative to support female faculty at the University of California Davis School of Medicine. Acad Med 2014;89:1462-6.

16. Carnes M, Morrissey C, Geller SE. Women"s health and women"s leadership in academic medicine: hitting the same glass ceiling? $J$ Womens Health 2008;17:1453-62. 